\title{
CHALLENGES AND OPPORTUNITIES FOR THE IMPLEMENTATION OF H-BIM WITH REGARDS TO HISTORICAL INFRASTRUCTURES: A CASE STUDY OF THE PONTE GIORGINI IN CASTIGLIONE DELLA PESCAIA (GROSSETO - ITALY)
}

\author{
V. Donato ${ }^{a^{*}}$, C. Biagini ${ }^{b}$, G. Bertini $^{\text {c }}$, F. Marsugli ${ }^{d}$ \\ a DISEG, Dept. of Structural, Geotechnical and Building Engineering, Polytechnic of Turin, 10129, Italy- vincenzo.donato@polito.it \\ ${ }^{b}$ DIDA, Dept. of Architecture, Univ. of Florence, 50123, carlo.biagini@unifi.it \\ ${ }^{\mathrm{c}}$ Building Engineer - gabriele.bertini@ording.gr.it \\ ${ }^{\mathrm{d}}$ Student - Specialisation School of the Architectural and Landscape Heritage, DIDA, Dept. of Architecture, Univ. of Florence - \\ francesca.marsugli@unifi.it
}

KEY WORDS: H-BIM, Cultural Heritage; (SfM) Structure from Motion, (TLS) Terrestrial Laser Scanner, (UAV) Unmanned Aerial Vehicle; monitoring, interoperability

\begin{abstract}
:
Historical Building Information Modeling (H-BIM) has been widely documented in literature and is becoming more popular with government bodies, who are increasingly choosing to make its use mandatory in public procurements and contracts. Although the system seems to be one of the best approaches for managing data and driving the decision-making process, several difficulties arise due to the amount of effort required in the initial phases, when the data derived from a geometrical survey must be converted into parametric elements. Moreover, users must decide on a "level of geometrical simplification" a long time in advance, and this inevitably leads to a loss of geometrical data.

From this perspective, our research describes a procedure to optimize the workflow of information for existing artefacts, in order to achieve a "lean" H-BIM. In this article, we will analyse two aspects: the first relates to the level of accuracy in a digital model created from the two different point clouds achieved from laser scanner and form images, while the second concerns the conversion of this information into parametric elements (Building Object Models- BOMs) that need to have specific characteristics.

The case study we are presenting is the "Ponte Giorgini" ("Giorgini Bridge") in Castiglione della Pescaia (Grosseto - Italy).
\end{abstract}

\section{INTRODUCTION}

The aim of Cultural Heritage $(\mathrm{CH})$ digitalization is to achieve a virtual digital model that represents an exact copy of the original existing artefact, with the main purpose of interpreting, analysing and disseminating the cultural and scientific results of the studies. This model can be used for two main purposes: firstly, to collect information which can protect the cultural significance of the building's heritage and secondly, achieve a virtual tool that can be used to better define a restoration strategy for the heritage that we are going to study.

The process usually starts with a survey campaign in order to achieve all the necessary data for rebuilding a digital model. Often this stage is related to the gathering of geometrical information, supported by the historical sources, to achieve a complete knowledge framework for the artefact.

Until now, the digital model has been used as a digital archive to store several kinds of information, from the traditional twodimensional representations of plan, elevation and section as well as $3 \mathrm{D}$ view representations.

However, the survey stage cannot be exclusively confined to a "boundary shell reconstruction" but instead must go towards an in-depth level of diagnostic assays that can give additional information about the internal composition of the elements and highlight possible critical issue in the existing structure.

In this context, new digital tools, developed using reverse engineering techniques, can help to extend our knowledge beyond the geometrical boundary through analyses (both physical and mechanical) that cannot be carried out manually, as they require computer processors. The digital model could be used as an "analyser bench" on which a series of experiments can be conducted, with the aim of semantically enriching the geometrical model and steering the process towards data management rather than just the issue of representation.

One possible approach could be to use BIM (Building Information Modeling), a method for information management during the building design process. Although this system originated as a primary methodology in the construction sector [1], in recent years it has gained international acclaim in the field of building heritage information management and its representation $[2,3]$. In the case of the digitalization of existing artefacts with artistic and historical significance, this method was defined as H-BIM (Historical Building Information Modeling) [4]. The main issue behind this reverse engineering process is related to the generation of parametric elements from captured geometric data. As in similar approaches to digital reconstruction, the process is highly time-consuming both in terms of the semantical recognition of geometrical elements (such as planes, surfaces, volumes, and primitive or complex geometric shapes) and modelling, and of the recognition of a vocabulary (such as vaults, pillars, pilasters, arches, gables, trusses, etc.), which is based on the operator's knowledge and manual modeling work, despite the recent development of automated semantic recognition processes [5].

Moreover, the quality of the model is related to the "level of approximation" or the "level of simplification" that is applied during the modelling phase, in comparison with the real object. This adds a metric "error" into the parametric model, in general greater than uncertainty held by the point cloud raw data [6] which cannot be eliminated with the currently-available technology. Accordingly, the level of approximation of the parametric elements must be calibrated as a function of BIM use

Corresponding author 
in order to avoid unmanageable models in terms of $\mathrm{MB}$, and achieve "lean models" that can be used for analytical purposes. In this work and on the basis of a literature review, a methodological approach will be defined that can move from a scan to H-BIM with particular regard to historical infrastructure, a topic still little addressed.

Through the analysis of a case study, the Giorgini Bridge in Castiglione della Pescaia (Grosseto), it was possible to demonstrate the advantages and limitations of this procedure, especially in relation to the effort of achieving the BOMs as much as correspondents and not deviated for the original survey data. This particular case was selected due to the complexity of its geometry: several elements are hidden and it is difficult to acquire the geometric data using laser scanning and photogrammetry. This case offers an example of the typology of historical infrastructure that has not been addressed yet in the literature. Advantages and limitations will be discussed later in this article using numerical data.

\section{STATE OF ARTS}

\subsection{Data acquisition: TLS, SfM and UAV}

The technological advancements that have led to significant changes in the field of 3D modeling are mainly related to the optical active sensors, better known as TLS (Terrestrial Laser Scanning) [7], and optical passive sensor, such as the digital photogrammetry approach (Close Range or Unmanned Aerial Vehicle), that nowadays are totally automatized through SfM techniques (Structure from Motion) by processes derived from the Computer Vision. In both cases (TLS and SfM), the final output is a point cloud or a $3 \mathrm{~d}$ mesh model that can be used as tracking reference systems for the definition of parametric elements suitable for the BIM model.

The literature shows that improvements in digital photogrammetry that mean that we can consider it a reliable technique in the $3 \mathrm{D}$ acquisition field, comparable with results from laser scanners [8-12].

The decision of choosing one of the two techniques before mentioned (TLS of SfM) could be done in relation of the morphology and the accessibly of the area (due to the maneuverability of the tools) but, at the same time, connected on costs evaluation.

Therefore, UAVs represent one of the emerging technologies and can be equipped with high-resolution cameras or even light TOF laser scanners [13]. They can be used for monitoring and emergency management of historical heritage, [14] especially when the heritage is not accessible. UAVs make it possible to overcome the limitations of a survey carried out from ground level which, for obvious reasons, do not allow the acquisition of information from impossible points of view [15].

Although the application of SfM and TLS to architectural objects and building heritage (including the H-BIM approach) has been well-documented in the literature, no reference has been made to infrastructure with historical significance.

In this case study, we would like to propose extending the analyses (if possible) to incorporate the whole cultural heritage, thus also including historical infrastructures that need restoration.

\subsection{H-BIM}

H-BIM is the acronym for Historical Building Information Model and is the new frontier of Cultural Heritage Management of Information, formalized only in recent years [4]. This application (H-BIM) reveals a number of unusual challenges and modeling pitfalls [16]. The process involves several techniques and the final result of an H-BIM is influenced by the procedure applied during the survey phase [17].

There are two main aspects to achieving an H-BIM model. The first relates to the process of converting survey data into parametric elements and how the model is semantically parsed and decomposed, inserting a separation in an element that by its nature does not exist, whilst the second relates to the definition of BIM use [18] that will heavily influence the modeling stage. The issue of accuracy in the modeling phase has been widely discussed in the literature $[2,19,20]$. The general opinion is that it is necessary to declare the "level of deviation" from the point cloud, adding this information to produce a texture that represents the distance from reality.

Moreover, the semantic parsing has important consequences for the individuation of the parametric objects' vocabulary, a library of "Building Object Models" (BOMs), which can establish a system of topological relationships [21].

The creation of digital libraries of parametric objects is considerably more complex, being possible only through a coordinated effort of survey, analysis and classification of the historical building compounds [20].

Although there are some systems of automatic recognition [5], the procedures are still in their early stages and cannot be applied to ordinary BIM works.

The modeling strategies of BOMs (Building Object Models) can be diversified and have to be calibrated from the study of manuals and historical treatises that describe the technology node, which cannot always be acquired through non-invasive investigations. A deeper modeling level must be calibrated as a function of the final purposes of the BIM analysis, that in the literature is defined by the BIM use. For instance, a model set up for energy analyses must be simplified due to the fact that only some information must be sent to the calculation software, at the expense of the detailed representation in the digital model.

In the literature, it is necessary to define a (Level of Development) [22] LoD in order to drive the modeling effort. This can be expressed by two components: one related to the information, LoI (Level of Information), and one related to the Geometry, LoG (Level of Geometry). Currently, the LoD information is not a normed concept, and will be inserted in the new Italian legislation UNI 11337-2017 [23]. In the near future, it is desirable that international organizations devote themselves to defining a glossary of terms related to the culture of historic materials, the classification of building elements, and related characteristics and attributes.

This is the first necessary degree of "interoperability", which can enable the effective development of BIM modeling in the field of historical heritage.

\section{H-BIM METHODOLOGY: ACQUISITION, CONVERSION AND INFORMATION MANAGEMENT}

The H-BIM procedure usually starts with a preliminary study that consists of a semantic parsing of all of the model, individuating an abacus of entities (BOMs) that constitute the entire artefact (BIM), traced on geometrical and technical data.

Moreover, the purpose of the final analysis will condition both the modelling phase and will direct the survey phase. As a result, it is necessary to decide early in advance on a suitable level of information for data exchange and sharing among the several specialist software analysis and BIM tools, thereby limiting information loss. This process can be synthesized in three main phases related to the treatment of information, which are to: acquire (1), convert (2) and manage and analyze (3).

The first phase (1) could be carried out by integrating different surveying techniques, often calibrated as the function of the 
area's morphology and the accessibility of the place. In recent years the literature has offered examples of how SfM can generate equivalent results, in metric terms, as laser scanners [24]. Due to their physical and historical complexity, the elements of a historical building include a good amount of heterogeneous data, and thus require a specific thematic survey. For this reason, the collected data always should be interpreted to obtain a useful digital model for the defined aims.

To reach a suitable level of accuracy of initial information for the implementation of the digital model it is necessary to have a thorough knowledge of the artefacts, which is also conducted through historical and archival investigations [3].

We will avoid going into detail on the technical aspects of point cloud acquisition through TLS and photogrammetry, as these have been discussed extensively in other works, and will limit ourselves to those operational activities that are related to guaranteeing interoperability between the various disciplines. Used individually, these survey systems do not enable us to acquire all the total information of the survey but they must be used in an integrated manner with each other, supported by a traditional topographic network to geo-reference the data.

To achieve a suitable point cloud suitable for the purposes of BIM, it is advisable to use the principle of the "realization of a lean model" in order to guarantee the best way of sharing information. This principle starts from the realization of a "lean point cloud", because some information will be lost during the process of conversion from points to parametric elements. A technique could be to use multi-scalar and multi-detailed point clouds, where the general one (an entity hosting "container") includes the other. The decision to take a multi-detailed scan is subject to a semantic parsing of the point cloud, which then in turn can be used for the generation of the various BOMs.

The second phase (2), of conversion into BIM, is closely related to the understanding of the interoperability level that the model must have in the BIM process chain.

A management technique (as described for the point cloud) for a digital model could be to develop a multiscale BIM model, where the BIM "container" (the generic one) is a simplified version with a low level of detail that can hold a sub-model in itself, with a growing level of detail and information.

At the operational level, it is necessary to recognize a system of reference (plane and line of reference, grids and levels) that can trace all the 3D entities, and to use it for generating the BOMs. The main difficulty is to generate a catalogue of customizable building object models that will represent the Cultural Heritage. These will vary according to era, territorial peculiarities, and characteristics expressed by the geographical area, according to the construction techniques; these conditions, different in each case, influence the BIM application, the level of detail (LoD) and the management of the representation of the digital model [16]. In the third phase (3), the aim is to guarantee the greatest amount of information for any maintenance work or renovation project, allowing all updates to be made in progress during the life of the assets.

In this case, there are two main aspects of this process: the first is related to information storage in the model, and the second is "query of information" thought the model, with the aim of driving the decision making process.

All the information will be stored in an internal database that is automatically organized by the BIM model. Not all of the model's parameters can be edited and managed outside the BIM software, and so require the use of plug-ins or external applications dedicated to solving particular problems. Usually, the information could be brought back to the collection of degradation information and the state of preservation to conduct structural analysis from viewpoints, highlighting any critical object.

Querying the model is the most interesting part in the management phase, because it can give important information about the examined object and helps define the type of intervention to be carried out, driving the decision-making process.

Currently, the traditional media for communication are based on a paper format, that are integrative part of the contract procurements. It is likely that in the near future the traditional paper-based media will be abandoned in favour of digital media (such as laptops and tablets) where the user can interact digitally without needing to print anything.

One possibility could be to use this type of model via web. To do this, a great deal of work is needed to prepare this new type of platform and to understand which techniques can support the communication of a huge amount of information (3D model but also two-dimensional information) included in the internal database.

The interactive management of the elements, through the ability to visualize endless views from the internal database, gives us the opportunity to virtually "compose and decompose" the building as we desire. The ability to model, edit, view, compare and represent entities can help to highlight strategic decisions, and is an enormous advantage for solving critical operating situations, controlling costs and reducing the risks involved during work phases.

\section{THE CASE STUDY: GIORGINI'S BRIDGE}

The case study we are presenting is the "Ponte Giorgini" ("Giorgini Bridge") in Castiglione della Pescaia (Grosseto Italy). The bridge was built to cross the Bruna River and was designed by the mathematician and civil engineer Gaetano Giorgini. It was commissioned by Leopold II, and was his first project for the reclamation of the Maremma area.

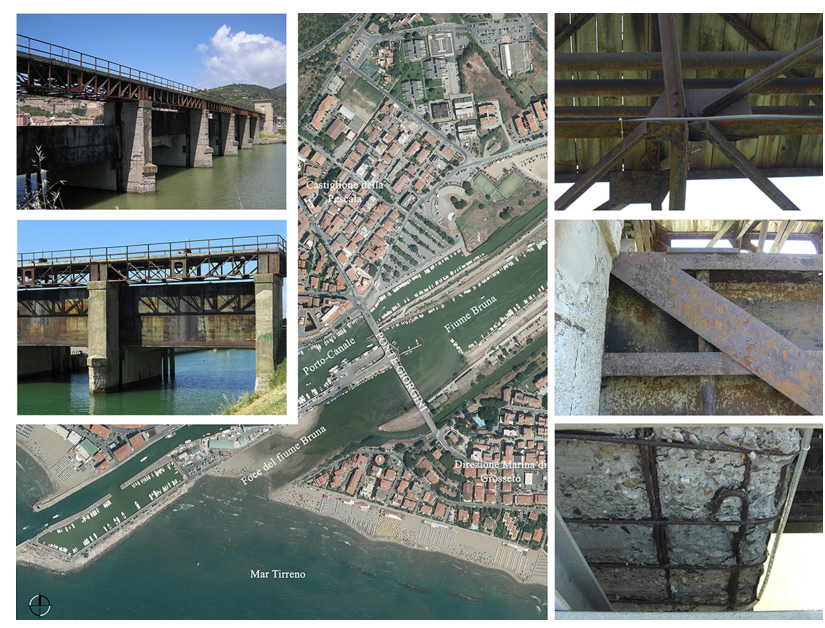

Figure 1. The Giorgini Bridge

The idea was to build a bridge with three floodgates ("cateratte a bilico") that could prevent the water of the Bruna River from mixing with the salty sea water. When works began in 1827 , it was believed that this "blending" of the waters was the main cause of malaria. Giorgini studied ways to separate the two different flows of water and the bridge was inaugurated in 1828 . In 1898, it became possible to ascertain that malaria was in fact spread by the Anopheles mosquito, destroying the popular belief that the disease came from marsh plant waste. 
The bridge was 26 meters wide and 12 meters high, and was composed of two lateral shoulders, lowered round arches and pylons. Between these pylons were the three floodgates consisting of a metal frame encased in oak.

The floodgates rotated on an iron pin and were closed either by hand or automatically by the force of the high-tide current, preventing seawater from entering the marsh. At low tide they would be opened by the force of the lake water that was thus discharged into the sea.

\subsection{Survey campaign and technical data}

The survey was conducted by acquiring the geometrical data with a laser scanner, as well as conducting a photogrammetric survey using a drone. In addition, the geometrical measuring was supported by an a to a topography network (a polygon) for the phases of the survey.

The survey was carried out by integrating, in order: total station and GPS survey, realization of a photosets though the use of a drone and the realization of a point cloud from a laser scanner.

The first type of survey was carried out through a total station SOKKIA SET3 130-R3 and supported by a GPS receiver TOPCON GR-3 and a series of optical prisms.

An open polygon has accordingly been set composed of five stations, whose position has been stored and localized with a GPS detector based on the conventional terrestrial system WGS84.

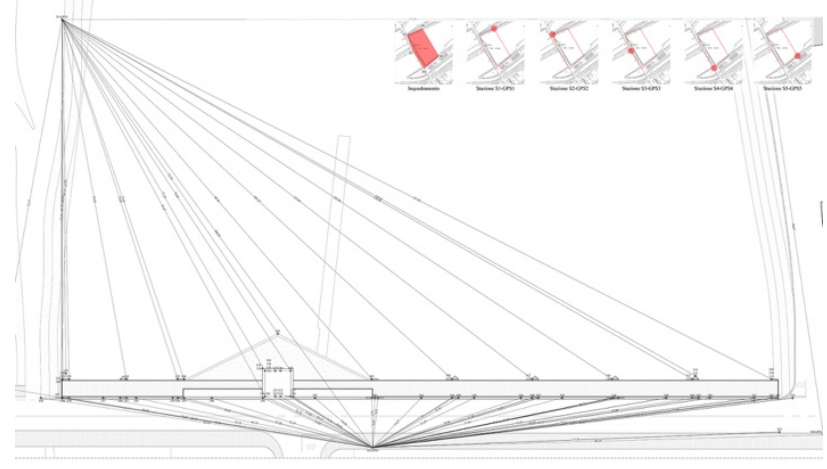

Figure 2. Traditional survey through Total Stations

The second type which can be discerned is that of photographic type, which is necessary for an analysis of the photo-modeling study object; this was done through the use of a drone. For the case in question, a survey could be carried out with a Phantom DJI 3 Professional during the early hours of the morning when the influx of traffic and pedestrians is very small. During the survey, the drone mostly flew near the river Bruna, where the underlying presence of pedestrians was negligible.

The phases of a UAV survey could be summarized as follows: assembly of the drone and general checking (front battery installation and verification of charge, checking for software updates, support of information storage through SD cards); calibration of the camera (horizontal and vertical calibration) and definition of the home; definition of the flight area, path and flight altitude.

The flight plan of the drone was set using the Altizure application, which uses GPS technology to define the area to be detected and the flight path. The use of GPS makes it possible to obtain geo-localized images. This feature allow to get a georeferenced model localized planimetrically and altimetrically, already oriented with true north.
The software used for processing the image was Agisoft PhotoScan that allows the creation of a mesh model archived from a series of passages (relative and absolute orientation of the pictures and alignment of the camera for achieving a sparse cloud, generation of the dense cloud and 3D mesh and build texture through UV Mapping, which is applied directly on the mesh providing a visually more pleasant result).

The result of the process in Agisoft PhotoScan, in addition to quality, the amount of photo shot and the complexity of the object modeling, is strongly linked to the specifications of the processing computer. The object under examination has a high longitudinal development, considering that the area set in the flight plan is approximately $200 \times 20 \mathrm{~m}$, which means obtaining a large amount of points. Moreover, the points recognized by PhotoScan elaboration of the point cloud can be even more numerous if the relief is generated by a laser scanner, which is able to beat 100 to 1000 points per second.

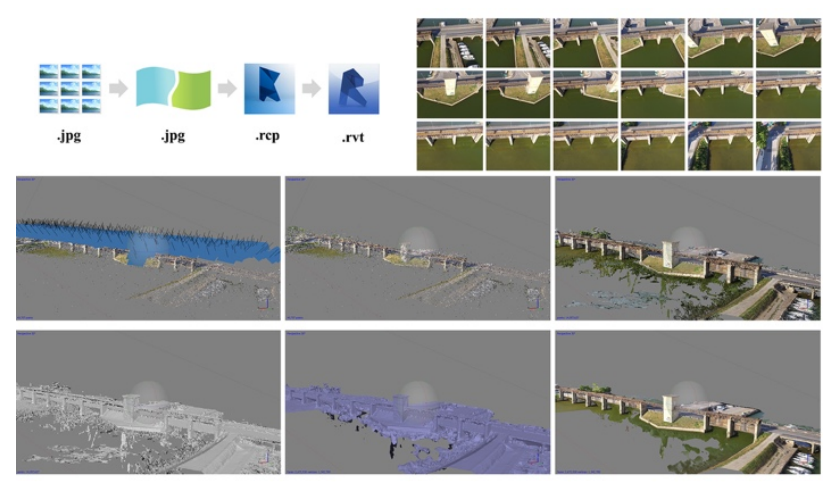

Figure 3. SfM reconstruction of the geometry through UAV

The third type of survey was conducted with a laser scanner, FARO FOCUS CAM2, and this last support was used as reference and to make a comparison in terms of displacement between the two point clouds (clouds achieved through a photogrammetrical approach and TLS).

The comparison in terms of "deviation of the cloud of points", to evaluate the difference between the two clouds generated using different data acquisition technologies, was performed with CloudCompare software. This application is able to process 3D point clouds and models created by triangular mesh. It was originally designed to make comparisons between two 3D point clouds generated by a 3D laser scanner with another cloud of points or a triangular mesh. CloudCompare provides a range of basic and advanced tools for the editing and rendering of $3 \mathrm{D}$ point clouds.

Some errors were detected from the non-correspondence of point clouds, due to the mismatch of clouds of points and the inability of the two major techniques to collimate the same points. In fact, the survey with a drone offers a great deal of information about surfaces placed at high altitudes which are not visible from ground level or with laser scanners. On the other hand, the laser scanner can capture a lot of detail in areas with a high level of concentration of points (for example, in the vicinity of the lattice) where the aerial survey with the drone was not able to assimilate information, given the distance and the instrumental precision. 


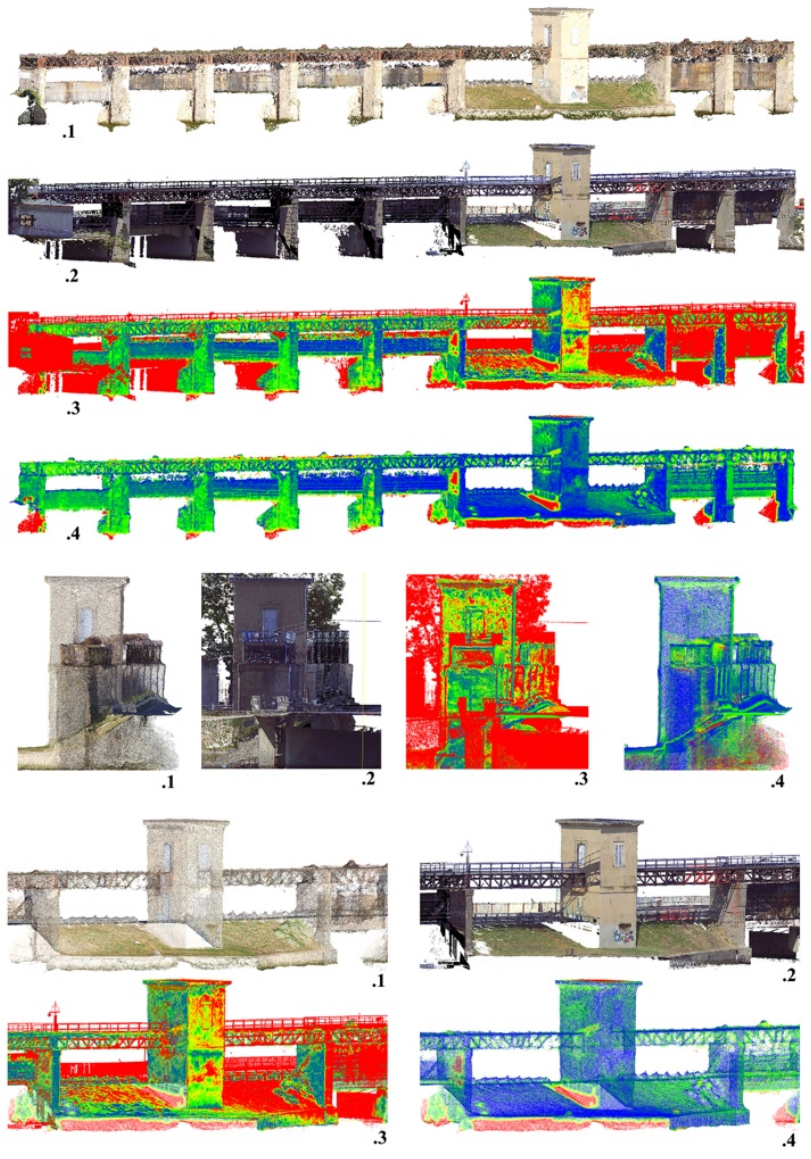

In the image depicted above are reported: 1 - point clouds generated from UAV, 2 - point clouds generate from laser scanner, 3 - comparison with the primitive point cloud, 4 comparison with the cleaned point cloud)

\subsection{H-BIM procedure and level of accuracy}

The path followed so far resulted in a good working basis for the creation of a model containing information that can be updated and integrated over time, which is extremely useful for the management of the object of study.

The H-BIM is based on assumptions other than those used in the application of BIM for new buildings, as historical, cultural and social standards need to be added to the architectural heritage objects, taking into consideration the building's own identity.

In order to proceed with the insertion of the point cloud in BIM software, Revit Autodesk, the point cloud was exported from Photoscan in the format .las. It was necessary to use an intermediate step with Autodesk Recap, which made it possible to convert the point cloud into the .rpc format supported by Autodesk Revit.

Finally, using the point cloud imported to Revit, integrated with a topographical survey with the total station and GPS and direct measurements taken at the site, it was possible to reconstruct the three-dimensional model of the H-BIM Ponte Giorgini.

For developing the H-BIM model that could represent this particular historical infrastructure, it was necessary to semantically deconstruct it and BOMs were defined from the main structural elements, up to detailing elements.

Figure 4. comparison of data

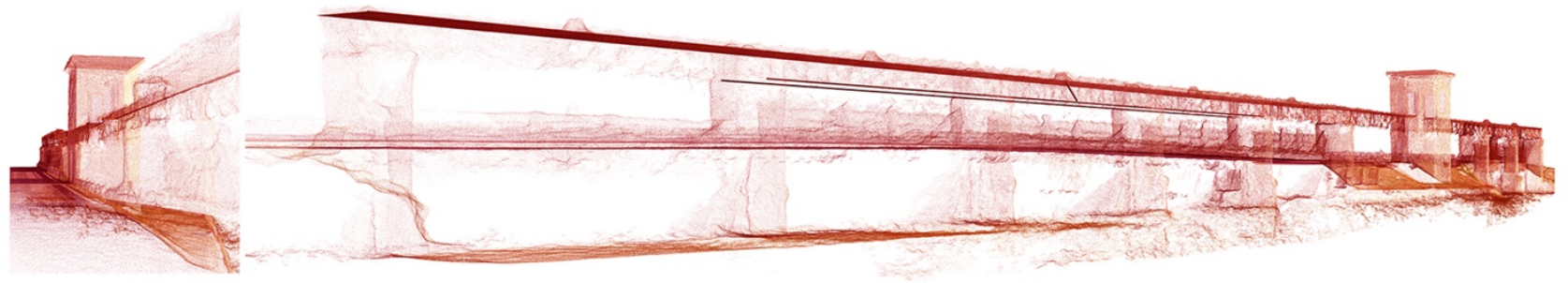

1. Point cloud generated with Photoscan

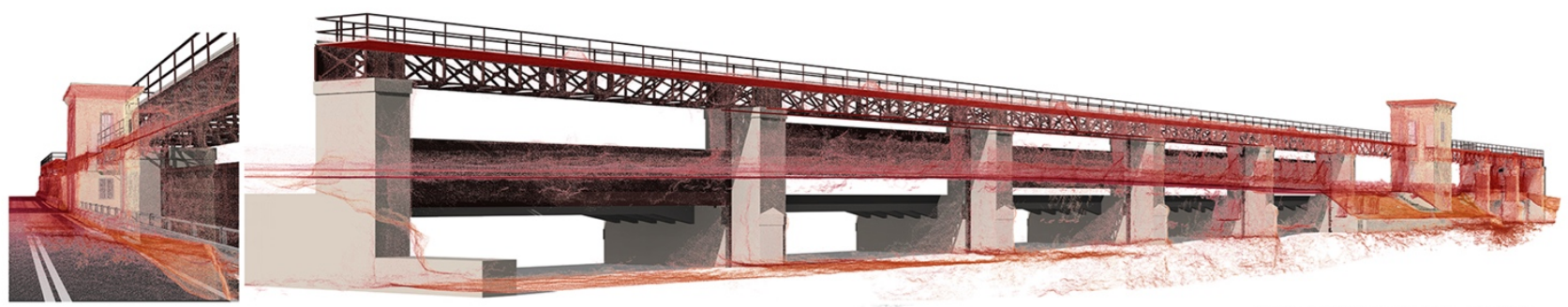

2. From point cloud to H-BIM
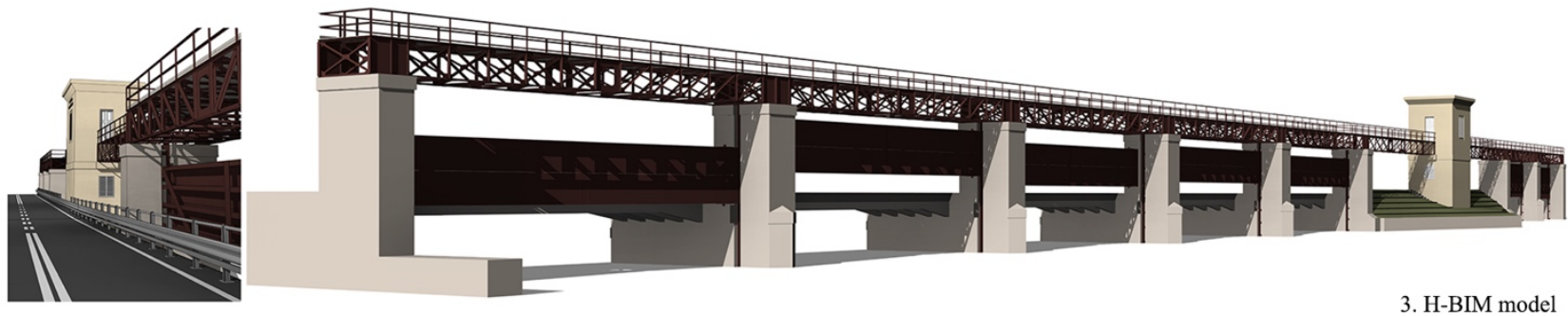

Figure 5. H-BIM process: from point cloud to H-BIM 


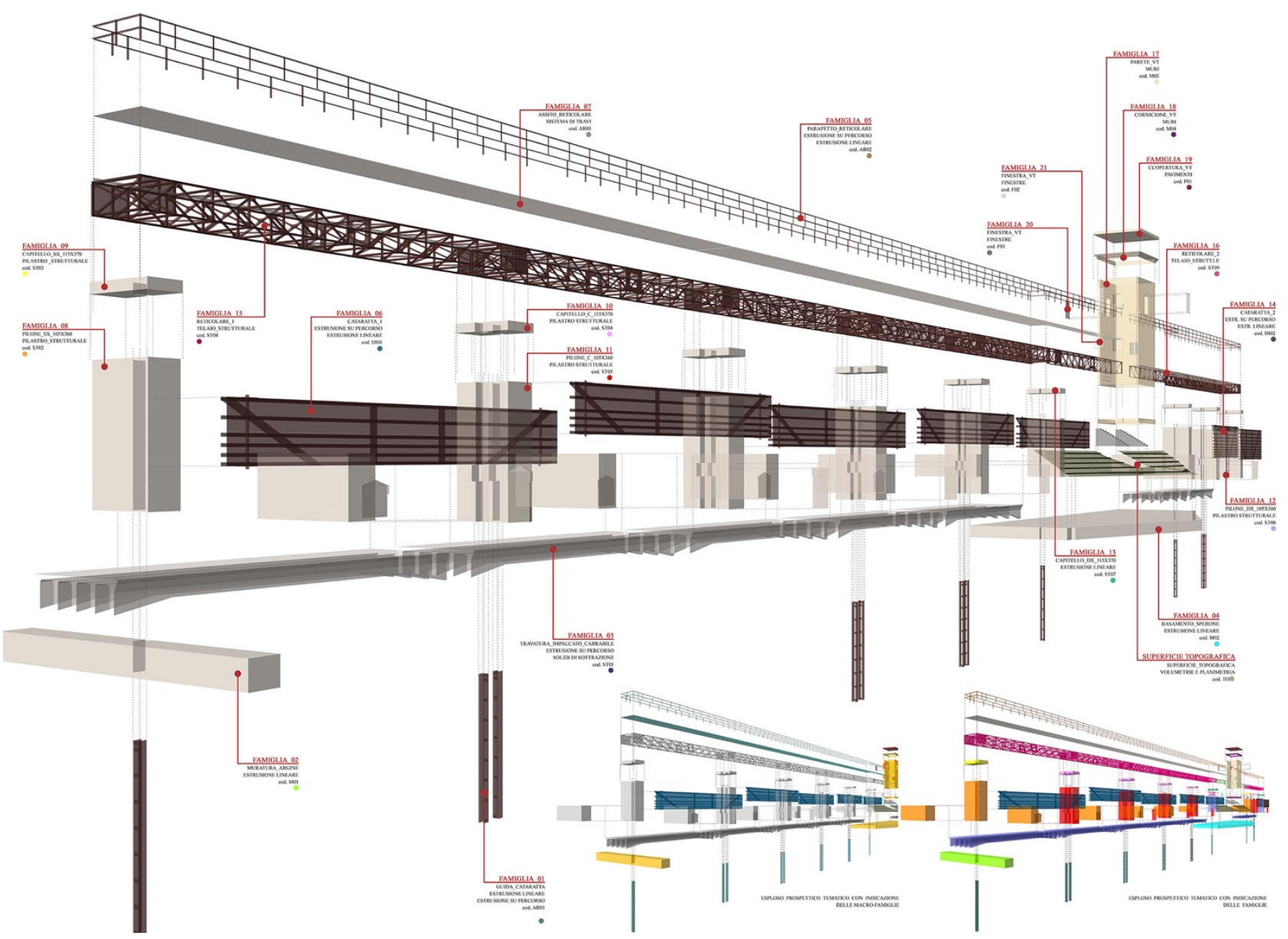

Figure 6. H-BIM process: from point cloud to H-BIM

The last step, of modeling in Autodesk Revit, enables exporting in various formats by different users (both architectural and structural purposes). Therefore understands the importance behind the creation of a BIM model, whose basic concept is to file interoperability. The software used is only one possible option, considering the evolution and vastness of the IT market in the field of $3 \mathrm{D}$ modeling.

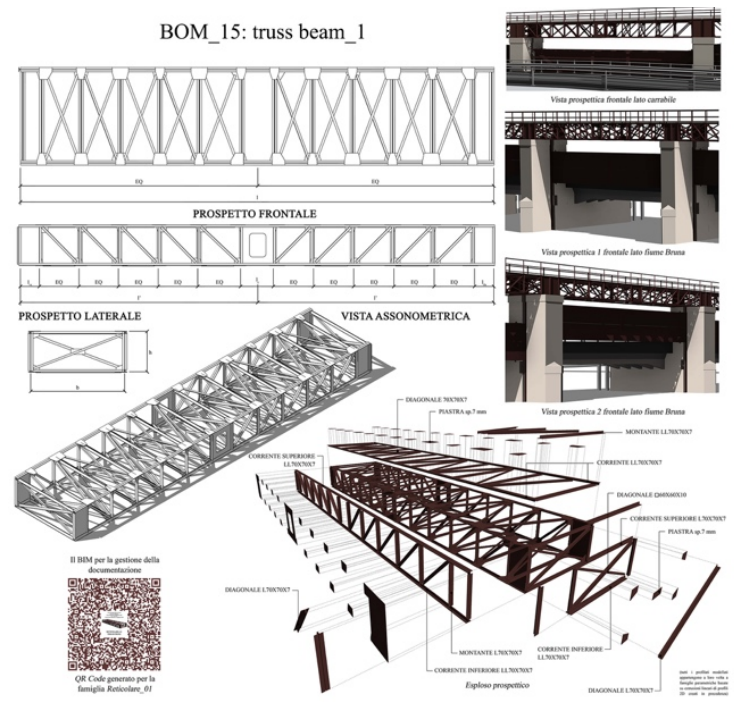

Figure 7. Sample of Historical BOM: truss beam_15

\subsection{Individuation of the state of deterioration}

Currently the bridge is in an advanced state of deterioration. Both the reinforced concrete structures and lattice steel structures have been severely compromised by salt, considering the high level of aggressiveness present at the site. Moreover, two floodgates in the channel are locked and out of service: they denote signs of deterioration due to the oxidation of the iron.
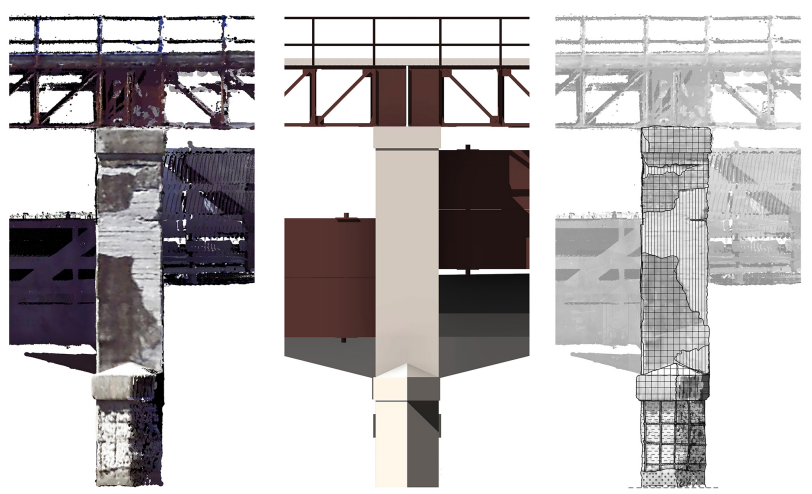

Figure 8. State of deterioration of a pillar (orthophotos, BIM Model and deterioration)

Therefore, restoration work is necessary for all the reinforced concrete structures (framing and pillars), as well as an 
intervention to safely put in the truss beam's steel structure due to a deterioration of the loadbearing elements, which is at risk due to the extension along the bridge.

The information regarding the state of deterioration was added to each BOM as a texture and transmitted two-dimensionally. This information can be added into the internal database.

The colored texture was generated with Agisoft PhotoScan, was possible to render an orthophoto that wasused to extract texture which can be applied to each element (BOMs), and to estimate the degradation surfaces, tracing two-dimensional hatches on the surface of the BOM that represents the degraded area that requires intervention.

The deterioration could be filtered by type and parametrically estimated by calculating the intervention area subdivided by typology. This kind of application is fundamental for achieving a parametric entity of the restoration work and highlighting the most critical parts within the structure.

\section{RESULTS AND CONCLUSION}

This paper describes an integrative procedure for obtaining an $\mathrm{H}-$ BIM by integrating several survey techniques to achieve the best result in terms of precision of parametric elements (BOMs).

The bridge represents a very challenging object of study due to its morphology. The recognition of the empty spaces between trusses and beams, both with laser scanners (due to the cone's shadow occluding the element behind the object) and the SfM approach (that does not recognize elements of detail), is difficult to achieve and needs to be tackled using several approaches.

In some cases, it is not possible to totally automate the method: a manual modelling intervention is needed to correct the element, integrating information from a direct survey.

From the case study, the final result was made possible by integrating all the survey procedures (TLS and SfM for UAV) in order to achieve a complete point cloud as a reference for the development of the H-BIM model.

In general, to obtain a model suitable for structural purposes, the level of accuracy applied throughout the process was too high for the final purpose.

Further studies will consider other types of diagnostic investigations. The next challenge will be to understand how to insert all the information deriving from diagnostic investigation into the H-BIM model and reference it within the model or in a database.

\section{ACKNOWLEDGEMENTS}

The authors would like to thank the $\mathrm{Cb} 6$ (Consorzio della Bonifica 6 Toscana Sud) and the Centro Servizi di Consulenza e Progettazione Copernico S.r.l. from Montalcino (SI) that they for allowing the use of the material to the authors.

\section{REFERENCES}

C. Eastman, P. Teicholz, R. Sacks, K. Liston, BIM Handbook: A Guide to Building Information Modeling for Owners, Managers, Designers, Engineers and Contractors, $2^{\circ}$ Edition, John Wiley \& Sons Inc., New Jersey, 2011. doi:10.1002/9780470261309.

[2] R. Quattrini, P. Clini, R. Nespeca, L. Ruggeri, Measurement and Historical Information Building: challenges and opportunities in the representation of semantically structured 3D content Misura e Historical Information Building: sfide e opportunità nella rappresentazione di contenuti 3D semanticamente, Disegnarecon. 9 (2016) 11.

[3] C. Biagini, P. Capone, V. Donato, N. Facchini, Towards the BIM implementation for historical building restoration sites, Autom. Constr. 71 (2016) 74-86. doi:10.1016/j.autcon.2016.03.003.

[4] M. Murphy, E. McGovern, S. Pavia, Historic building information modelling-adding intelligence to laser and image based surveys, ISPRS-International Arch. .... XXXVIII (2011) 2-4. http://adsabs.harvard.edu/abs/2011ISPAr3816W...1M.

[5] I. Armeni, O. Sener, A. Zamir, H. Jiang, 3D Semantic Parsing of Large-Scale Indoor Spaces, CVPR. (2016) 1534-1543. doi:10.1109/CVPR.2016.170.

[6] U.S. General Services Administration's Public Buildings Service: Office of the Chief Architect, GSA Building Information Modeling Guide (Series 1-8), (2009).

[7] M. Lemmens, Terrestrial Laser Scanning, in: GeoInformation, Springer Netherlands, Dordrecht, 2011: pp. 101-121. doi:10.1007/978-94-007-1667-4_6.

[8] P. Grussenmeyer, T. Landes, T. Boegtle, K. Ringle, Comparison methods of terrestrial laser scanning, photogrammetry and tacheometry data for recording of cultural heritage buildings, in: ISPRS Congr., 2008: pp. 213-218.

http://www.isprs.org/congresses/beijing2008/proceedin gs/5_pdf/38.pdf.

[9] R. Kadobayashi, N. Kochi, R. Furukawa, Comparison and Evaluation of Laser Scanning and Photogrammetry and Their Combined Use for Digital Recording of Cultural Heritage, in: Int. Arch. Photogramm. Remote Sens. Spat. Inf. Sci. 35 (Part B5), 2004: pp. 401-406.

[10] D.D. Lichti, S.J. Gordon, M.P. Stewart, J. Franke, M. Tsakiri, Comparison of digital photogrammetry and laser scanning, in: Int. Soc. Photogramm. Remote Sens., 2002: pp. 39-44.

[11] A.M. Manferdini, M. Galassi, Assessments for 3d reconstructions of cultural heritage using digital technologies, Int. Arch. Photogramm. Remote Sens. Spat. Inf. Sci. XL-5 W (2013) 167-174.

[12] R. Roncella, C. Re, G. Forlani, Performance evaluation of a structure and motion strategy in architecture and cultural herita, Int. Arch. Photogramm. Remote Sens. Spat. Inf. Sci. 38 (5/W16) (2011) 285-292.

[13] I. Colomina, P. Molina, Unmanned aerial systems for photogrammetry and remote sensing: A review, ISPRS J. Photogramm. Remote Sens. 92 (2014) 79-97. doi:10.1016/j.isprsiprs.2014.02.013.

[14] E. Candigliota, F. Immordino, Low Altitude Remote Sensing by UAV for monitoring and emergency management on historical heritage, in: XV Convegno ANIDIS L'Ingegneria Sismica Ital., 2013. doi:10.13140/2.1.4508.8642.

[15] A. Meschini, E. Petrucci, D. Rossi, F. Sicuranza, Point cloud-based survey for cultural heritage. An experience of integrated use of range-based and image-based technology for the San Francesco convent in Monterubbiano, in: Int. Arch. Photogramm. Remote Sens. Spat. Inf. Sci. - ISPRS Arch., 2014: pp. 413-420. doi:10.5194/isprsarchives-XL-5-413-2014.

[16] R. Volk, J. Stengel, F. Schultmann, Building Information Modeling ( BIM ) for existing buildings Literature review and future needs, Autom. Constr. 38 (2014)

109-127. doi:10.1016/j.autcon.2013.10.023.Abstract.

[17] D. Oreni, R. Brumana, S. Della Torre, F. Banfi, L. 
Barazzetti, M. Previtali, Survey turned into HBIM: the restoration and the work involved concerning the Basilica di Collemaggio after the earthquake (L'Aquila), ISPRS Ann. Photogramm. Remote Sens. Spat. Inf. Sci. II-5 (2014) 267-273. doi:10.5194/isprsannals-II-5-267-2014.

[18] R.G. Kreider, J.I. Messner, The Uses of BIM: Classifying and Selecting BIM Uses, University Park, PA, USA, 2013. http://bim.psu.edu/Uses/the_uses_of_BIM.pdf.

[19] R. Brumana, D. Oreni, A. Raimondi, A. Georgopoulos, A. Bregianni, From survey to HBIM for documentation, dissemination and management of built heritage: The case study of St. Maria in Scaria d'Intelvi, in: 2013 Digit. Herit. Int. Congr., IEEE, 2013: pp. 497-504. doi:10.1109/DigitalHeritage.2013.6743789.

[20] D. Oreni, R. Brumana, A. Georgopoulos, B. Cuca, Hbim for Conservation and Management of Built Heritage: Towards a Library of Vaults and Wooden Bean Floors, ISPRS Ann. Photogramm. Remote Sens. Spat. Inf. Sci. II-5/W1 (2013) 215-221. doi:10.5194/isprsannals-II-5W1-215-2013.

[21] C. Biagini, V. Donato, Building Object Models (BOMs) for the documentation of historical building heritage, in: H.C. Lomonaco, S. Barba (Eds.), EGraFIA 2014 Revis. Del Futur. Previs. Del Pasado. V Congr. Int. Expresión Grá ca En Ing. Arquit. Y Carreras A Nes Y XI Congr. Nac. Profesores Expresión Grá ca En Ing. Arquit. Y Carreras A, EGraFIA 2014, Rosario (Argentina), 2014. doi:10.13140/RG.2.1.1108.2005.

[22] BIMforum, Level of Development Specification, 2015. http://bimforum.org/lod/.

[23] UNI, UNI 11337:2017 - Construction and civil engineering works - Digital management of information processes of construction, (2017).

[24] C. Santagati, M. Lo Turco, From structure from motion to historical building information modeling: populating a semantic-aware library of architectural elements, J. Electron. Imaging. $26 \quad$ (2016) 11007. doi:10.1117/1.JEI.26.1.011007. 